\title{
Engineering curriculum development in microsystems
}

\author{
Yongjun Lai ${ }^{1}$ \\ ${ }^{1}$ Department of Mech. and Materials Eng. \\ Queen's University, Kingston, ON, K7L 3N6 \\ lai@me.queensu.ca \\ Shafaat Ahmed Bazaz ${ }^{2}$ \\ ${ }^{2}$ CMC Microsystems, Kingston, ON, K7L 3N6
}

\begin{abstract}
Microsystems are a rapidly developing technology that integrates Micro-electro-mechanical systems (commonly known as MEMS) and microfluidics devices with microelectronics and optoelectronics circuits. Due to increasing demand and opportunities from these fields, universities are introducing or have introduced MEMS/Microfluidics courses to their students at undergraduates and graduate levels. By its nature, the field is multidisciplinary and requires various backgrounds when integrating all components of Microsystems as described above. The current challenges in this area are design, fabrication and testing the microsystem devices. This brings various constraints on both the instructors and the students from the point of teaching and learning aspects. Designing a typical microsystem requires the use of modeling and simulation tools from multi energy domains (circuit simulators, multiphysics analysis, 3D modeling, fluidic flows etc). Fabrication methods have recently been evolved from traditional microelectronics fabrication techniques to more complicated micromachining technologies (bulk vs. surface micromachining, LIGA vs. Deep Reactive Ion etching etc). Testing of Microsystems goes beyond traditional electrical testing to the motion analysis of the moving parts on the microsystems. In recent years, the application of microsystems have also been moving away from traditional telecommunication and entering into new areas like health care, energy, environment, automobile and biotechnology. This makes the teaching of microsystem technologies more challenging to fulfill the needs of students entering in Microsystems from existing disciplines (electrical, mechanical, physics, etc.) with limited background on all parts of microsystems. In addition to the multidisciplinary nature of Microsystems, limited resources (small number of design platforms versus large number of students), absence of supportive funding $v$ s. high cost of prototyping, limited time frame vs. long fabrication periods, restrictive opportunities for students to have hands-on design experience make it difficult to offer such courses at graduate and undergraduate levels.

In this paper, we discuss developing a new Microsystems course curriculum with emphasis on MEMS in university environment, particularly at Queen's University in Canada. This curriculum is designed in a teamproject-based manner but in modular form. The lecture will be delivered by two main instructors and some guest instructors for different topics. The team members for each project have complementary background or coming from different discipline. The pertinent resources at Queen's University, including such in CMC Microsystems will be available to the students which solves the shortage of resources for teaching.
\end{abstract}

\section{Introduction}

Micro-Electro-Mechanical Systems (MEMS) is a relatively new field that facilitates IC (Integrated Circuit) or new emerged micromachining technology to fabricate microactuators, microsensors, micromechanisms. The development of MEMS has fostered the field to expand into many inter- or crossdisciplinary fields, such as, optical communication (optical MEMS or MOEMS, Mico-Opto-ElectroMechanical Systems), biological applications (BioMEMS), radio frequency communications (RF MEMS), and Microfluidics, etc. Even though mechanical researchers have stepped into the fields later than the researchers do from electrical engineering, mechanical engineering plays a key role 
in MEMS fields the same as it does in traditional fields. The movement of mechanical engineers into MEMS research is in line with the demands of $21^{\text {st }}$ century engineers [1-3].

The rapid growth of MEMS put current curriculum into an awkward situation. Most of Canadian Universities had offered MEMS course at graduate level, such as, MEMS courses at Dalhousie University, University of Alberta, etc. Due to high demand of MEMS course for undergraduate students, some Canadian universities offered relevant courses at undergraduate level, some of them even opened a new program or option, such as, nanotechnology program at University of Waterloo, and Mechantronics \& Embeded systems as a mechanical option at University of Victoria. Some of the courses offered at Canadian institutions are listed in Table 1 [4].

\section{Table 1. List of courses offered at Canadian} Universities.

\begin{tabular}{|c|c|c|c|}
\hline Course Title & $\begin{array}{c}\text { Institutio } \\
\text { n }\end{array}$ & Instructors & Cycle \\
\hline $\begin{array}{l}\text { Intro. to } \\
\text { Microfluidics }\end{array}$ & $\begin{array}{l}\text { U. of } \\
\text { Toronto }\end{array}$ & Dr. Li (left) & Grad. \\
\hline $\begin{array}{c}\text { MEMS device } \\
\text { design and } \\
\text { modeling }\end{array}$ & $\begin{array}{l}\text { U. of } \\
\text { Calgary }\end{array}$ & Dr. Spiewak & Grad. \\
\hline $\begin{array}{c}\text { MicroSytems } \\
\text { Technologies } \\
\text { (MST) }\end{array}$ & $\begin{array}{l}\text { U. of } \\
\text { Calgary }\end{array}$ & $\begin{array}{c}\text { Drs.. Kaler \& } \\
\text { Dalton }\end{array}$ & Grad. \\
\hline $\begin{array}{c}\text { Micromachining and } \\
\text { MEMS }\end{array}$ & $\begin{array}{l}\text { U. of } \\
\text { Manito. }\end{array}$ & $\begin{array}{l}\text { Dr. Cyrus } \\
\text { Shafai }\end{array}$ & Grad. \\
\hline $\begin{array}{c}\text { Microfabrication } \\
\text { techniques } \\
\end{array}$ & SFU & Dr. Gray & Both \\
\hline $\begin{array}{c}\text { Biomedical } \\
\text { Microdevices and } \\
\text { Systems } \\
\end{array}$ & SFU & $\begin{array}{c}\text { Dr. } \\
\text { Parameswaran }\end{array}$ & Grad. \\
\hline $\begin{array}{c}\text { Structural Design and } \\
\text { Manufacture of } \\
\text { Microdevices } \\
\end{array}$ & McGill & $\begin{array}{c}\text { Dr. } \\
\text { Vengallatore }\end{array}$ & Grad \\
\hline $\begin{array}{l}\text { Design and } \\
\text { Fabrication of } \\
\text { MEMS } \\
\end{array}$ & Concor. & Dr. Stiharu & Both \\
\hline $\begin{array}{c}\text { Microelectronic } \\
\text { Sensors }\end{array}$ & Carleton & Dr. Tait & Grad. \\
\hline \begin{tabular}{|c|} 
Intro./Application to \\
Nanotechnology \\
\end{tabular} & $\begin{array}{l}\text { U. of } \\
\text { Alberta }\end{array}$ & Dr. Backhouse & Both \\
\hline MEMS & Dalhousie & Dr. Hubbard & Grad. \\
\hline $\begin{array}{l}\text { Design and Fab of } \\
\text { Micromachines \& } \\
\text { Micromechanisms }\end{array}$ & Concor. & Dr. Packirisamy & Grad. \\
\hline
\end{tabular}

As a prestigious university in Canada, Queen's University recently has offered two relevant courses to graduate students by Department of Physics:
"Introduction to Microfabrication", and "Advanced Topics in Micro and Nano Technology". These two courses are targeted towards graduate students; furthermore, the contents are shifted to science instead of engineering. There is no entry level MEMS course for graduate students and undergraduate students yet. The primary objectives of the present effort are to incorporate interdisciplinary fields, to expose students to recently emerged technology, and to develop MEMS researchers.

\section{Curriculum Structure}

The primary goal of this curriculum development is to integrate fundamental courses from both mechanical and electrical engineering with emphasis on mechanical engineering. Basic knowledge obtained from some of other courses will be referred to when different topics are addressed. The courses that are adopted for this curriculum at Queen's University are listed in Table 2. Traditional mechanical engineering courses cover a very broad range of knowledge, such as, heat transfer, solid mechanics, dynamics and vibrations, etc., which should be applied and enhanced by application in this course. On the other hand, courses from electrical engineering, such as, Introductory electric circuits and machines, electronics $I$, and corresponding labs provide basic theoretical and practical experience on fundamental electrical and electronics knowledge.

As aforementioned, the majority of the course will be upper level senior undergraduate students and junior graduate students; therefore, there is no prerequisite for them. The IC and MEMS fabrication process will be covered in the early sections of the course. Students are expected to obtain basic understanding of IC and MEMS fabrication process, such as, lithography, deposition, and etching, etc.

The major topics of the curriculum are:

1) Introduction to microfabrication (IC and MEMS fabrication process).

2) Basic theories or principles for MEMS devices, such as actuators, sensors, mechanisms, and micropumps, etc.

3) Size effects: Scaling Laws.

4) Design methodologies, Design CAD Tools, and design practice.

5) Design Projects (using MUMPs [5]). 
Table 2. Required courses for MEMS curriculum

\begin{tabular}{|c|c|c|}
\hline \multicolumn{2}{|c|}{ Mechanical Engineering } & $\begin{array}{c}\text { Electrical Eng. and } \\
\text { others }\end{array}$ \\
\hline \multirow{7}{*}{$\begin{array}{c}2^{\text {nd }} \\
\text { year }\end{array}$} & $\begin{array}{c}\text { MECH } 212 \\
\text { Design Techniques }\end{array}$ & $\begin{array}{l}\text { CIVL } 220 \text { Statics \& } \\
\text { Solid Mechanics }\end{array}$ \\
\hline & $\begin{array}{c}\text { MECH } 213 \\
\text { Manufacturing Methods }\end{array}$ & \multirow{2}{*}{$\begin{array}{c}\text { ELEC } 210 \\
\text { Introductory Electric } \\
\text { Circuits \& Machines }\end{array}$} \\
\hline & $\begin{array}{c}\text { MECH } 215 \\
\text { Instrument. \& Measur. }\end{array}$ & \\
\hline & $\begin{array}{c}\text { MECH 230 } \\
\text { Thermodynamics I }\end{array}$ & $\begin{array}{c}\text { ELEC-252 } \\
\text { Electronics I }\end{array}$ \\
\hline & $\begin{array}{c}\text { MECH 241 } \\
\text { Fluid Mechanics I }\end{array}$ & \multirow{2}{*}{$\begin{array}{c}\text { ELEC } 290 \\
\text { Electrical \& } \\
\text { Computer Eng. Lab }\end{array}$} \\
\hline & $\begin{array}{c}\text { MECH } 270 \\
\text { Materials Sci. \& Eng. }\end{array}$ & \\
\hline & $\begin{array}{c}\text { MECH } 228 \\
\text { Kinematics \& Dynamic }\end{array}$ & \\
\hline \multirow{8}{*}{$\begin{array}{c}3^{\text {rd }} \\
\text { year }\end{array}$} & $\begin{array}{c}\text { MECH } 314 \\
\text { Manufacturing Eng. }\end{array}$ & $\begin{array}{c}\text { ELEC371 } \\
\text { Microprocessor } \\
\text { Systems } \\
\end{array}$ \\
\hline & $\begin{array}{c}\text { MECH } 321 \\
\text { Solid Mechanics II } \\
\end{array}$ & \\
\hline & $\begin{array}{c}\text { MECH } 323 \\
\text { Machine Design }\end{array}$ & \\
\hline & $\begin{array}{c}\text { MECH } 328 \\
\text { Dynamics and Vibration }\end{array}$ & \\
\hline & $\begin{array}{c}\text { MECH } 330 \\
\text { Thermodynamics II }\end{array}$ & \\
\hline & $\begin{array}{c}\text { MECH 341 } \\
\text { Fluid Mechanics II }\end{array}$ & \\
\hline & MECH 346 Heat Transfer & \\
\hline & $\begin{array}{c}\text { MECH } 350 \\
\text { Automatic Controls }\end{array}$ & \\
\hline
\end{tabular}

\section{Teaching Strategies Through Fabless Prototyping}

Fabless prototyping requires more emphasis on design while using standard fabrication methods. We propose to use this concept in designing the course on MEMS. Though this method of developing MEMS devices limits the designers to work within the design rules of the standard process but on the other side designer can optimize the design within the given fabrication constraints of the standard process. Here we summarize some of the advantages of fabless prototyping method:

- Avoiding time consuming, labour consuming and sophisticated fabrication methods that requires the presence of an expensive clean room facility. Learning the basics of fabrication process steps with more emphasis on device design.

- Develop expertise in the designing functional MEMS devices using analytic and numerical skills while using the existing powers of such simulation tools.

- Using standard process makes its easy for nonmaterial science/engineering student to design devices right from proof of concept to more functional devices in less iteration of fabrications.

From education point of view, this method delivers more knowledge and hand-on experience to the students within the short time duration of a term course. This method has been used largely in the teaching of microelectronics community in past 30 years to develop highly qualified personals especially in engineering disciplines.

On the other side, designing a MEMS device requires the expertise from mainly electrical and mechanical engineering disciplines. MEMS commercial CAD tools (MEMSPro, Coventor, Intellisense) accomplish the following tasks [6] in semi automated way:

- Planar mask layout involving non-Manhattan geometries and curved edges

- Process sequence simulation/emulations and three-dimensional device structure generation. The most common tools used are 3D Model Generator in MEMSPro, MEMulator in Coventor.

- Multi-physics numerical modeling for physical simulation of three-dimensional solid structures using finite/boundary element methods. Tools like Comsol, ANSYS, Algor are well suited for such simulations.

- Automatic lumped parameter extraction of structures for device-level behavioural modeling. Circuit simulators like Spice, Saber are generally used for the simulation of such models.

- Behaviour modeling at system level simulation of MEMS devices with integrated electronics. This requires the use of tools like VHDL-AMS, Matlab.

These modeling levels can be arranged in both bottom-up and top-down approaches [6]. The important point to note is that these design and simulation tools generally come from electrical and mechanical engineering disciplines and cross intersection of the tools affects the learning of student coming from the opposite discipline.

\section{Education Innovation}

An educational environment, in which students can consistently assess their research progress with the stated goals, will help develop skills useful for future 
careers. This course will introduce several innovations in teaching such an interdisciplinary course. These innovations range from team teaching by Queen's faculty and scientific staff from CMC Microsystems ${ }^{a}$, to group case study seminar. Recognizing the educational significance of these new approaches, this course will emphasize fundamental principles and problem solving by introducing practical case study and group projects. The use of multi-media technology for in-class demonstration will be enhanced.

Students entering this course will have senior or graduate standing in physical sciences or engineering disciplines. Given the interdisciplinary nature of the topic, the course should attract students from various disciplines ranging from basic science to engineering. Group-based projects will be assigned to students. Group members will have different backgrounds, or come from different disciplines. The various background of a group will ensure that students from different disciplines interact and learn from each other. Such interaction would be beneficial to make up for any deficiencies in background required to take this course. This may be not suitable for a traditional course.

After basic operating principles of MEMS devices and typical commercial fabrication processes are covered, efforts of the curriculum will be shifted to design tools, layout preparation, and design rules. In this course, design CAD tool (MEMSPro) will be introduced, with detailed examples from MicraGEM, MetalMUMPs, and PolyMUMPs. Design project will be practical topics in selected areas. Each student will get chance to submit his/her design at footprint area of approximately $200 \mu \mathrm{m}$ x $200 \mu \mathrm{m}$ with PolyMUMPs process $\left(\right.$ MEMScap $\left.^{\mathrm{TM}}\right)$. The MEMS designs considered viable for fabrication from the research point of view would be manufactured through CMC Microsystem's fabrication services at the end of course. These fabricated chips will be used for testing by the microsystem researchers of the department and shall be part of the course in the following year. This design opportunity integrates the practical design skills and concepts which is directly valuable for students to develop careers in either research or industry.

\footnotetext{
a CMC Microsystems is an organization funded by Canadian government to support Canadian researchers in the development of microelectronics, MEMS, microfluidics, photonics devices and microsystems. Its headquarters locates at Queen's University, Kingston, Ontario.
}

Depending on the enrollment of the course, the curriculum may include techniques of how to convert layout from geometry modeling tools, such as, Solid Edge, AutoCAD, etc., into MEMSPro 2D layout (GDSII), which is the final format for fabrication. Some design project layout will be prepared using Solid Edge which is a familiar 3D modeling tool for mechanical engineering students at Queen's, and is free for them. This will make it easier to optimize the skills of students from mechanical design.

\section{Integrating Research Results}

Design Rule Check (DRC) is a critical component for design. Designers have to understand the fabrication process very well in order to make fabrication-success design. Most commonly, MEMS course will introduce some specific design rules, and students are required to follow the design rules carefully. By introducing such design rules, students may be restricted by such rules to come up with their innovative ideas. However, some of the rules may have space for violation. Design rules will be introduced in this curriculum as well. However, different from common MEMS curriculum development, some emphasis will lay on how to break design rules to make innovative design while still getting a functional prototype. The knowledge obtained through the MEMS researchers of the department about such violations will be incorporated in the course to align the research with education.

The following is an example that will be used for demonstration of how to break design rule. The example is to use PolyMUMPs process to fabricate a cantilever beam. Layout generator used in MEMSPro is L-Edit. Figure 1a is a 2D layout of a cantilever beam made of polyl layer, anchored to substrate. A poly2 layer cantilever is attached to poly1 cantilever by poly2-poly1 via at the end. The two cantilever beams have the same width and have 2 um vertical gap. If designers follow design rules exactly, this design can not be made because it breaks the design rule "poly 1 enclose poly 2 by $4 \mu \mathrm{m}$ ".

In the reality, the only risk for Fig. 1a design is that the two cantilever beams may not accurately aligned in vertical direction. However, that may be a trivial issue compared with flexibility for innovative design. For instance, to increase sensitivity of a comb-drive capacitive sensor, there are three possible ways: increasing comb fingers, or increasing thickness of the comb fingers, or decreasing the gap between comb fingers. Decreasing gap will encounter high risk of fabrication failure; therefore, this has to be avoided. Increasing number of comb fingers, results larger 
footprint of the design which is doable but not preferable. The third way is to increase the thickness of the fingers which is not achievable through design with no design rule violations. However, with solid understanding of the PolyMUMPs fabrication process, designer can add a large layer of poly2-poly1 via between poly2 and poly1 to connect these two separate layers (see Fig. 1c). Function of poly2-poly1 via layer is to etching a hole on the sacrificial layer (Oxide layer) between poly1 and poly2 and allows deposition poly2 on top of poly1. By doing this, a thicker structure can be produced (see Fig. 1d) as comb fingers for higher sensitivity capacitive sensors.

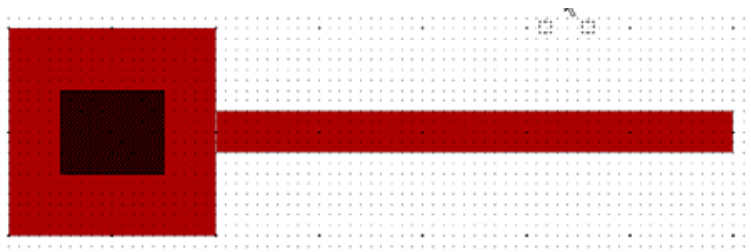

(a) 2D poly1 \& poly2 separated cantilevers

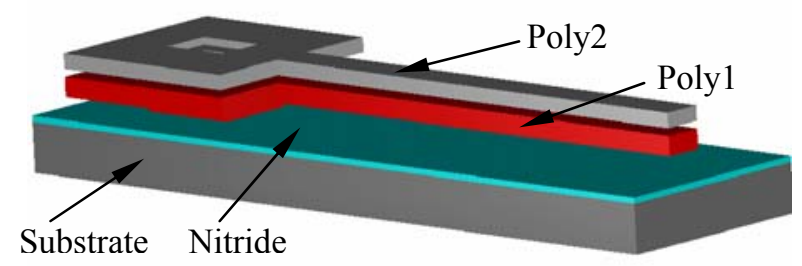

(b) 3D poly1 \& poly2 separated cantilevers

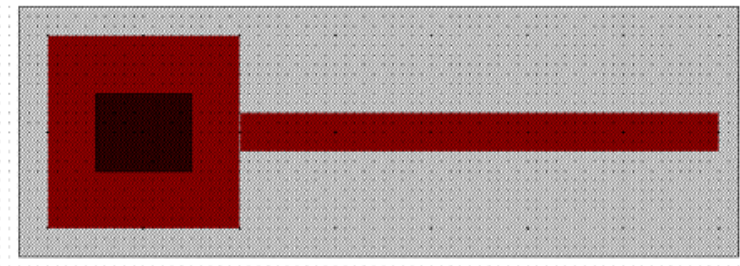

(c) 2D poly1 \& poly2 jointed cantilevers

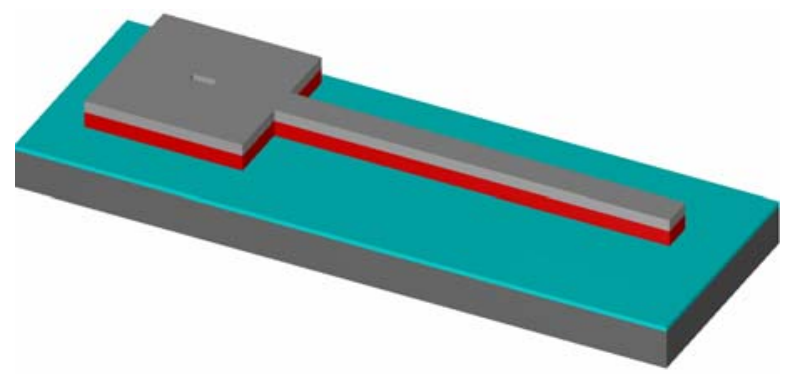

(d) 3D poly1 \& poly2 jointed cantilevers

Figure 1. 2D layout and 3D model of cantilever beams by breaking design rules.
By introducing such techniques rarely covered in a traditional MEMS course, students will be encouraged to study standard fabrication processes better and deeper. As the result of this, students are expected to know how to follow design rules and how to tactically make violations on design rules; also, students will be stimulated to explore new ideas and designs, while still using standard commercial fabrication processes.

\section{Conclusions}

A MEMS curriculum has been proposed for senior undergraduate mechanical engineering students standing at upper level and junior graduate students at entry-level. The challenges and innovativeness have been addressed. The final practice results and feedback will be investigated after the course is completed in the future.

\section{References}

[1] Lin, Liwei, "Curriculum Development in Microelectromechanical Systems in Mechanical Engineering", IEEE Transactions on Education, 44 (1), 2001, pp. 61-66.

[2] Pister, K., Engineering Education Design in an Adaptive System. Washington, DC: Nat. Academy, 1995.

[3] Kulacki, F.A., "The education of mechanical engineers for the $21^{\text {st }}$ century", JSME Int. J., ser. A, 39(4), pp. 467478, 1996.

[4] Gale, D., Bazaz, S. A., "Microsystems research and steps towards stabling the nano-community in Canada", the 11th Micramachine Summit, 1-4 May 2005, Richardson, Texas

[5] Koester, D., Majedevan, R., Shishkoff, A., and Marcus K., "Multi-User-MEMS Processes (MUMPs) introduction and design rules," rev.4, MCNC MEMS Technology Applications Center, Research Triangle Park, NC, July 1996. [6] Bazaz, S. A., "Design Methodology and Modeling Strategies for MEMS", Bulletin of Canadian Society of Mechanical Engineers, September 2003. 